\title{
Identifying short surface ligands on metal phosphide quantum dots $\dagger$
}

Cite this: Phys. Chem. Chem. Phys., 2016, 18, 17330

Received 24th May 2016, Accepted 13th June 2016

\author{
Edwin A. Baquero, $\ddagger^{a}$ Wilfried-Solo Ojo, $\ddagger^{a}$ Yannick Coppel, ${ }^{b}$ Bruno Chaudret, ${ }^{a}$ \\ Bernhard Urbaszek, ${ }^{a}$ Céline Nayral*a and Fabien Delpech ${ }^{* a}$
}

DOI: $10.1039 / \mathrm{c} 6 \mathrm{cp} 03564 \mathrm{~g}$

www.rsc.org/pccp

The control and understanding of the chemical and physical properties of quantum dots (QDs) demands detailed surface characterization. However, probing the immediate interface between the inorganic core and the ligands is still a major challenge. Here we show that using cross-polarization magic angle spinning (MAS) NMR, unprecedented information can be obtained on the surface ligands of $\mathrm{Cd}_{3} \mathrm{P}_{2}$ and $\operatorname{InP}$ QDs. The resonances of fragments which are usually challenging to detect like methylene or methyl near the surface, can be observed with our approach. Moreover, ligands such as hydroxyl and ethoxide which have so far never been detected at the surface can be unambiguously identified. This NMR approach is versatile, applicable to any phosphides and highly sensitive since it remains effective for identifying quantities as low as a few percent of surface atoms.

Over the last decade, quantum dots -QDs- have emerged as an important class of materials for applications ranging from electronics to biomedicine. ${ }^{1}$ These significant achievements have been made possible thanks to the development of procedures leading to nano-objects of controlled-shape, -structure, -composition and surface chemistry. This latter feature is obviously of key importance for the synthesis but it is also central for the chemical and physical properties of individual QDs as well as their ordered-assemblies. As an important example, the switching from insulating organic ligands to inorganic ones allows the establishment of conductive bridges between QDs. This has paved the way for applications such as LEDs, solar cells, electronic circuits, and photodetectors. ${ }^{2}$ While the concepts and the principles that have been established during these works could in principle be applied to a wide variety of materials, the vast majority of advances have been achieved for II-VI and IV-VI semiconductors. In contrast to the success story

\footnotetext{
${ }^{a}$ LPCNO (Laboratoire de Physique et Chimie des Nano-Objets), Université de Toulouse, INSA, UPS, CNRS, 135, avenue de Rangueil, F-31077 Toulouse, France. E-mail: fabien.delpech@insa-toulouse.fr, celine.nayral@insa-toulouse.fr

${ }^{b}$ Laboratoire de Chimie de Coordination, UPR-CNRS 8241, 205 route de Narbonne, 31077 Toulouse Cedex, France

$\dagger$ Electronic supplementary information (ESI) available: Further experimental details and characterization data. See DOI: 10.1039/c6cp03564g

$\$$ These authors have contributed equally to this work.
}

of these chalcogenides QDs, the chemistry of phosphides QDs has achieved only limited success to date. ${ }^{2,3}$ For example, InP QDs whose chemistry is the most developed, still suffer from comparably large size distributions $(>15 \%)$ and broad emission line widths (40-60 $\mathrm{nm}$ at FWHM), limited range of diameters and hence emission wavelengths (mainly 500-600 nm) and lower fluorescence quantum yields (generally $<60 \%$ ). ${ }^{3}$

Aiming at overcoming these limitations, significant efforts have been invested over the last decade into the clarifications of the mechanisms involved in the synthesis and the stabilization of the phosphide QDs. ${ }^{3-6}$ The point of convergence of these works is the surface of the QDs. In contrast to the now well-known surface chemistry of the lead and cadmium chalcogenides nanocrystals (NCs), ${ }^{7}$ that of phosphide QDs is much less understood and displays a diversity that does not seem to exist for selenides or sulfides. For instance, we have previously shown for InP QDs that $\mathrm{PO}_{x}$ (with $x=3$ and predominantly 4 ), $\mathrm{In}_{2} \mathrm{O}_{3}$, and $\mathrm{InO}_{y}(\mathrm{OH})_{3-2 y}$ $(y=0,1)$ species exist at the surface. ${ }^{8}$ The formation of these species is the direct consequence of the high oxophilicity of these QDs which react with water existing as a residual impurity in reactants or solvents or coming from side-reactions of ligands at high temperature. Given the extraordinary complexity of these phosphide QDs surface, the full characterization of the surface ligand is not an easy task. Among the various spectroscopic tools probing QDs surface at the molecular scale (as for instance, infrared, and $\mathrm{X}$-ray photoelectron spectroscopies), nuclear magnetic resonance (NMR) stands out. ${ }^{7 c, 9,10}$ This commonly available technique is probably the most effective because (i) many ligands display characteristic spectral features that allow their identification, (ii) it is nondestructive, easy to set up and it allows an analysis directly in the native environment, (iii) the free and bound species can be distinguished, and (iv) the ligand dynamics can be monitored. ${ }^{9,10}$ Nevertheless, an important and still open challenge for the characterization of $\mathrm{NC} /$ ligand systems, is to obtain a detailed picture of the QD surface for short ligands ${ }^{11}$ as could be the case of hydroxyl ${ }^{8 b, 12}$ or alkoxide. ${ }^{10 c, 11 b, 13}$ The observation of moieties close to the surface of QDs is extremely difficult for two main reasons: first, the NMR resonances are broadened due to dipolar 
couplings, chemical shift anisotropies, structural disorder and potential electronic effects of the nanoparticles -NPs- (including the Knight shift). ${ }^{7 c, 10,14}$ Second, the interface represents only a small proportion of the sample. In this communication, we describe our solution to this blocking point by using conventional solid state NMR. Using $\mathrm{Cd}_{3} \mathrm{P}_{2}$ and InP QDs as model systems, we show far-reaching capability for identifying surface fragments or ligands and in particular, the so far unobserved $\mathrm{P}-\mathrm{OH}$ fragment. Moreover, we demonstrate that concentrations as low as a few percent of surface atoms can be identified using this straightforward and easy to set-up method. The generality of this approach to other phosphide QDs is also provided and allow demonstrating the presence of hydroxyl and ethoxide at the surface of InP QDs.

It has been shown, ${ }^{8,15}$ that the analysis of surface QDs using the basic cross-polarization (CP) sequence MAS NMR is of high interest because it brings complementary information to those given by solution NMR: the low motion of the surface ligand can be advantageously used through the $\mathrm{CP}$ experiment to enhance the signals which are typically too broad and too weak to be not observable in solution. The $\mathrm{CP}$ experiment where magnetization is transferred from a proton nucleus to a spin nucleus of lower sensitivity $\left(\right.$ e.g. $\left.{ }^{13} \mathrm{C},{ }^{29} \mathrm{Si},{ }^{31} \mathrm{P}\right)$ relies on heteronuclear dipolar couplings. This effect is favored by the low motion and, it decreases fast with distance (inversely proportional to the cube of the distance). Thus, it can be used as a filter to probe neighboring fragments. On this basis, we have chosen to implement a double $\mathrm{CP}^{16}$ also named Forth and Back $\mathrm{CP}(\mathrm{FBCP})^{17}$ which has been recently used for nanoscale silica-based system involving ${ }^{1} \mathrm{H}$ and ${ }^{29} \mathrm{Si}$ nuclei. ${ }^{18}$ In our case, we utilize two consecutive CP transfers from the ${ }^{1} \mathrm{H}$ of the ligands to ${ }^{31} \mathrm{P}$ located at the surface of QDs, followed by CP from ${ }^{31} \mathrm{P}$ to ${ }^{1} \mathrm{H}$ close to the surface, allowing to probe distance less than $0.5 \mathrm{~nm}$. In addition, we have adapted the sequence for the general and challenging case of the NPs bearing mobile alkyl chain ligands, where the end groups of the ligands display sharp and intense NMR signal. It often prevents the detection of the broad and weak resonances of groups close to their surface. The case of phosphide QDs is well-suited for using the FBCP sequence for the three following reasons: (i) the NMR active ${ }^{31} \mathrm{P}$ nucleus is a $100 \%$ naturally abundant and a sensitive probe that can be used as a relay for the polarization transfer, (ii) the ${ }^{31} \mathrm{P}$ nucleus in phosphide QDs possesses long $T_{1}$ relaxation time (usually $T_{1}\left({ }^{31} \mathrm{P}\right)$ is between 20 and $\left.200 \mathrm{~s}\right)^{19}$ that is an important property for a good elimination of the residual ${ }^{1} \mathrm{H}$ magnetization, (iii) ${ }^{31} \mathrm{P}$ NMR is very sensitive to its chemical environment and it allows in this work to cross-check the validity of the observations made with the FBCP sequence.

In a first step, the potentialities of the FBCP sequence were tested using $\mathrm{Cd}_{3} \mathrm{P}_{2}$ QDs as a reference because they have important advantages as a model system. These QDs can be synthesized at RT and thus, side-reactions which are known to occur at high $\left(300{ }^{\circ} \mathrm{C}\right)$ or moderately high $\left(150{ }^{\circ} \mathrm{C}\right)$ temperature are avoided. ${ }^{8,20}$ In addition, the surface chemistry of these QDs is versatile and can be modified in order to introduce various ligands and to test the limits of this method.

First, we studied $\mathrm{Cd}_{3} \mathrm{P}_{2}$ QDs stabilized by a mixture of classical amine and carboxylate ligands namely hexadecylamine (HDA) a)

b)

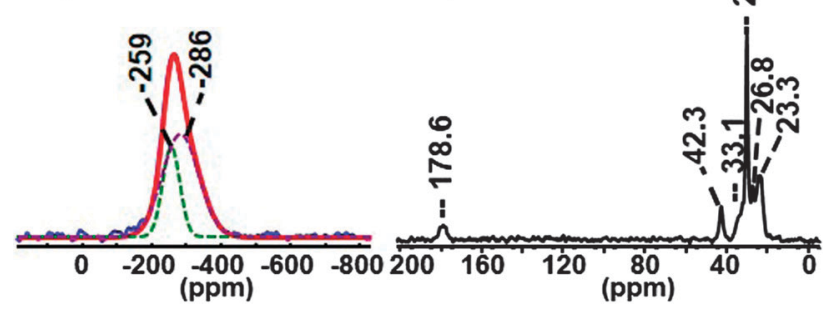

Fig. $1{ }^{31} \mathrm{P}$ Hahn-echo MAS (blue) NMR spectrum (spinning speed $20 \mathrm{kHz}$ ) compared to simulated spectrum (red) (a) and ${ }^{13} \mathrm{C}$ CP MAS NMR spectrum (spinning speed $16 \mathrm{kHz}$ ) of $\mathrm{Cd}_{3} \mathrm{P}_{2}$ QDs stabilized by a mixture of HDA and OAc (b).

and acetate (OAc). The QDs were prepared following a procedure previously described with octylamine instead of HDA that is the addition at room temperature of the phosphorus source $\mathrm{P}\left(\mathrm{SiMe}_{3}\right)_{3}$ into a solution containing 3 equiv. of $\mathrm{Cd}(\mathrm{OAc})_{2}$ and 7 equiv. of $\mathrm{HDA}^{20}$ After $2 \mathrm{~h}$ and the subsequent work-up, spheroidal $\mathrm{Cd}_{3} \mathrm{P}_{2}$ QDs of $2.4(0.3) \mathrm{nm}$ are obtained. The UV-Vis, PL spectra, XRD data and TEM picture are provided in Fig. S1 (ESI $\dagger$ ). Using the established NMR spectroscopy techniques available for the QDs analysis (solution and solid-state NMR studies), a first insight into both the inorganic and organic components can be gained. ${ }^{8,20}$ The ${ }^{31} \mathrm{P}$ CP-MAS showed only one sharp signal around $-250 \mathrm{ppm}$ corresponding to ${ }^{31} \mathrm{P}$ in the immediate proximity of the $\mathrm{Cd}_{3} \mathrm{P}_{2}$ NC surface (Fig. S2, ESI $\dagger$ ). In the ${ }^{31} \mathrm{P}$ Hahn-echo MAS NMR spectrum, a broad resonance was observed and shifted at low frequency (around $-270 \mathrm{ppm}$ ) because of the presence of a second component at $-286 \mathrm{ppm}$ as shown by the deconvolution in the Fig. 1a. This latter signal can be assigned to the inner ${ }^{31} \mathrm{P}$ atoms of the core of $\mathrm{Cd}_{3} \mathrm{P}_{2}$ QDs. Both ${ }^{31} \mathrm{P}$ resonances lie in the high-field range typically found for NPs of metal phosphides ${ }^{8,20}$ and are consistent with the formation of $\mathrm{Cd}_{3} \mathrm{P}_{2}$ as the only phosphorus-based material. Concerning the composition of the coordination sphere, ${ }^{13} \mathrm{C}$ CP MAS NMR experiments (Fig. $1 \mathrm{~b}$ and Fig. S3, ESI $\dagger$ ) show signals corresponding to carbon containing moieties that are in restricted motions as the ligand on NPs.

The presence of HDA and OAc at the surface is attested by the resonances of the methylene group located $\alpha$ to the amine functional group $(\delta=42.3 \mathrm{ppm})$ and of the acyl $(\delta=178.6 \mathrm{ppm})$ together with its methyl moiety $(\delta=23.3 \mathrm{ppm})$. While being much more sensitive than the NMR of all other nuclei, the up-to-date ${ }^{1} \mathrm{H}$ NMR methods remain not well-suited for the identification of the ligands. In the ${ }^{1} \mathrm{H}$ MAS NMR spectrum of the $\mathrm{Cd}_{3} \mathrm{P}_{2}$ QDs (bottom spectrum of Fig. 2), the only resonances clearly visible are located at $\delta 1.28$ and $0.89 \mathrm{ppm}$ and can be assigned respectively to those of the 14 methylenes (i.e. all the $\mathrm{CH}_{2}$ except the closest to the nitrogen atom) and the methyl moieties of the alkyl chain of HDA.

These resonances are sharp because the high mobility of the HDA alkyl chain at the methyl terminus strongly reduces the ${ }^{1} \mathrm{H}-{ }^{1} \mathrm{H}$ dipolar coupling that usually broaden the ${ }^{1} \mathrm{H}$ NMR signal. In contrast, the resonances which allow the identification of specific groups near the surface (methylene $\alpha$ to the amine functional group and the methyl group of acetate) are too weak to be observable. Similarly, in solution the ${ }^{1} \mathrm{H}$ NMR spectrum in $\mathrm{CDCl}_{3}$ (Fig. S4, ESI $\dagger$ ) 


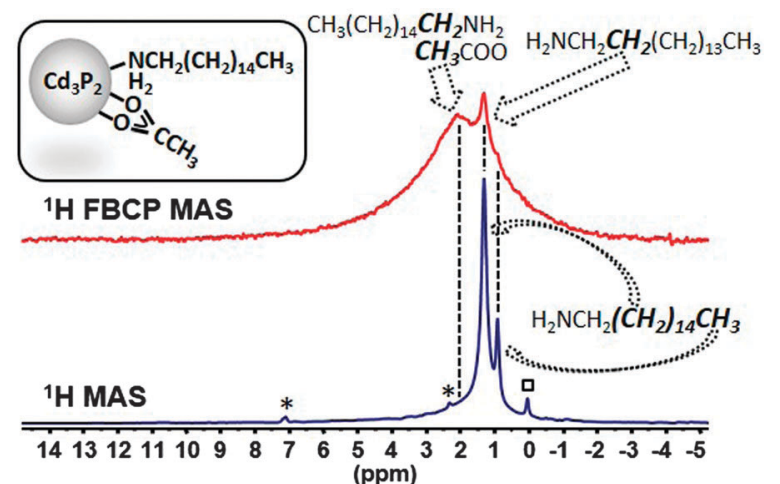

Fig. 2 Comparison of the ${ }^{1} \mathrm{H}$ MAS NMR and FBCP ${ }^{1} \mathrm{H}$ MAS NMR spectra (spinning speed $20 \mathrm{kHz}$ ) of $\mathrm{Cd}_{3} \mathrm{P}_{2}$ QDs stabilized by a mixture of HDA and OAc, (*: residual toluene, $\square$ : grease).

shows mostly sharp signals for the mobile groups of HDA (central methylenes at $1.28 \mathrm{ppm}$ and methyl groups at $0.90 \mathrm{ppm}$ ). However for these small NPs $(2.4(0.3) \mathrm{nm})$, very broad and weak resonances can be observed for the methylene $\alpha$ to $\mathrm{NH}_{2}(2.71 \mathrm{ppm})$ and the OAc methyl group $(2.01 \mathrm{ppm})$. Additional information can be gained with NOESY and DOSY experiments that evidenced strongly surface-bound OAc species and a mixture of strongly and weakly-bound HDA species (Fig. S5 and S6, ESI $\dagger$ respectively). Applying the upgraded FBCP sequence (see ESI $\dagger$ ) allows the enhancement of the protons close to the surface at the expense of the intensity of the peaks belonging to mobile fragments (Fig. 2). A new broad signal due to a resonance distribution centered around $2.1 \mathrm{ppm}$ can indeed be observed and assigned to the acetate and the methylene $\alpha$ to the amine functional group. This method, thus, addresses the current failure existing for ${ }^{1} \mathrm{H}$ MAS NMR, concerning the characterization of restricted motion fragments in the presence of mobile ones which is the most frequent situation in ligand-capped metal NC systems.

More interestingly, this method can be used to identify ligands that have been so far invisible. For this purpose, we have prepared $\mathrm{Cd}_{3} \mathrm{P}_{2}$ QDs displaying few hydroxyl ligands by adding small amounts of water (see Experimental part). For sake of clarity, these QDs will be noted $\mathrm{Cd}_{3} \mathrm{P}_{2}-\mathrm{OH}$ QDs. The UV-Vis, PL spectra, XRD data and TEM picture of $\mathrm{Cd}_{3} \mathrm{P}_{2}-\mathrm{OH}$ NCs are provided in Fig. S7 (ESI $\dagger$ ). Besides the resonances of the phosphides, the ${ }^{31} \mathrm{P}$ Hahn-echo MAS NMR spectrum displays a small peak which is barely visible at ca. 3 ppm (Fig. 3). The existence of this peak was confirmed using the ${ }^{31} \mathrm{P}$ CP MAS NMR experiment (Fig. 3). This resonance is assigned to oxidized phosphorus. ${ }^{8}$

The ${ }^{1} \mathrm{H}$ MAS NMR spectrum performed at $20 \mathrm{kHz}$ of the $\mathrm{Cd}_{3} \mathrm{P}_{2}-\mathrm{OH}$ QDs shows no clear difference with that of $\mathrm{Cd}_{3} \mathrm{P}_{2}$ QDs (Fig. S8, ESI $\dagger$ ). However, when applying the FBCP sequence, the resulting ${ }^{1} \mathrm{H}$ NMR spectrum displays on one hand a broad resonance around $\delta 2.1 \mathrm{ppm}$ similar to the one observed for the previous $\mathrm{Cd}_{3} \mathrm{P}_{2}$ QDs (methyl of acetate and methylenes located $\alpha$ and $\beta$ to the amine functional group). On the other hand, an additional broad resonance at higher frequencies and in particular, around $8 \mathrm{ppm}$ is clearly evidenced (Fig. 4). This latter signal is consistent with the oxidized phosphorus species identified in the ${ }^{31} \mathrm{P}$ CP MAS NMR spectra of $\mathrm{Cd}_{3} \mathrm{P}_{2}-\mathrm{OH}$ QDs. It can be assigned to

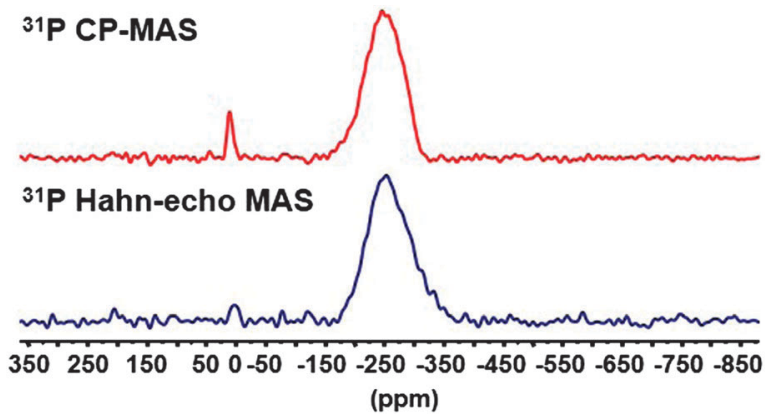

Fig. $3{ }^{31} \mathrm{P}$ Hahn-echo MAS NMR and ${ }^{31} \mathrm{P}$ CP MAS NMR spectra of $\mathrm{Cd}_{3} \mathrm{P}_{2}-\mathrm{OH}$ QDs (spinning speed $20 \mathrm{kHz}$ ).

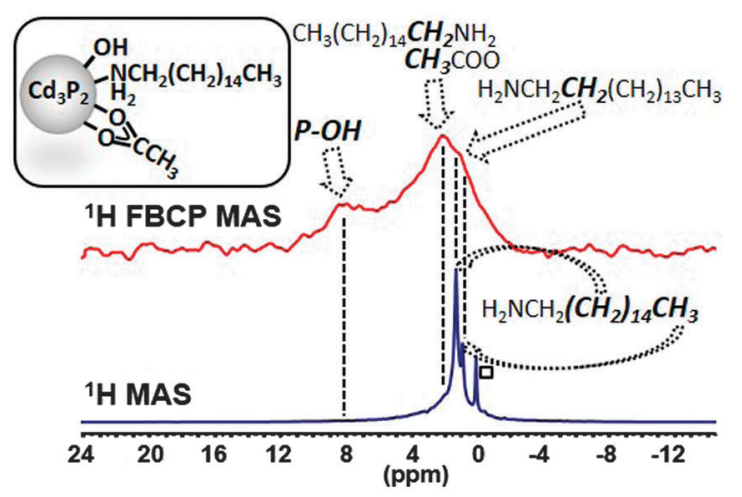

Fig. 4 Comparison of the ${ }^{1} \mathrm{H}$ MAS NMR and FBCP ${ }^{1} \mathrm{H}$ MAS NMR spectra (spinning speed $20 \mathrm{kHz}$ ) of $\mathrm{Cd}_{3} \mathrm{P}_{2}-\mathrm{OH}$ QDs ( $\square$ : grease).

the acidic phosphate protons $\mathrm{P}-\mathrm{O}-\mathrm{H}$ of $\mathrm{HPO}_{4}{ }^{2-}\left(\right.$ or $\left.\mathrm{H}_{2} \mathrm{PO}_{4}{ }^{-}\right)$moiety as previously observed with calcium phosphates. ${ }^{21}$ The broadness of this resonance can be interpreted as the consequence of different hydrogen bonded environments and water content. The chemical shift of hydroxyl is dependent on hydrogen bonding (the stronger the hydrogen-bond, the higher the chemical shift) and chemical exchange with surface-adsorbed water. ${ }^{21}$ Moreover, an evaluation of the amount of $\mathrm{OH}$ which is detected can be undertaken: the size of the QDs $(2.3(0.3) \mathrm{nm})$ implies that around $30 \%$ of the $\mathrm{P}$ atoms are located at the surface, this value being also supported by the ${ }^{31} \mathrm{P}$ Hahn-echo MAS NMR spectrum shown in Fig. 3. Given the percentage of $\mathrm{P}-\mathrm{O}-\mathrm{H}$ ( $2 \%$ of the total $\mathrm{P}$ atoms) which is determined by integrating the surface of the $\mathrm{P}-\mathrm{O}-\mathrm{H}$ resonance in the ${ }^{31} \mathrm{P}$ Hahn-echo MAS NMR spectrum, we can estimate that 2/30 i.e. $c a$. only $7 \%$ of the $\mathrm{P}$ surface atoms are $\mathrm{P}-\mathrm{O}-\mathrm{H}$. Thus, this shows that besides being effective for identifying moieties close to the surface, this method is also highly sensitive. The implications of the presence of hydroxyl ligand at the surface go beyond the mere issue of the identification of new ligands: hydroxyl has been recently shown to play a key role in stabilizing the (111) facets of PbS NCs. Moreover, it is suspected to be at the origin of (i) the deterioration of the optical and electrical properties of $\mathrm{PbSe}^{22}$ and $\mathrm{PbS}^{12 b}$ QDs-based films and (ii) the InP QDs growth inhibition. ${ }^{8,5 e, 6 b}$ Last, as small-sized anionic ligand, it plays a central role to establish charge neutrality that could not be achieved by sterically hindering fatty carboxylate. ${ }^{12 a}$ Thus, this 
tool is highly relevant in view of controlling the cation/anion stoichiometry in QDs as a tool to further manipulate QD material properties. ${ }^{23}$

The FBCP sequence used here can be directly applied to other phosphides QDs like the highly valuable InP QDs. ${ }^{3}$ In this case, it allows unraveling so far unknown ligand at the surface of QDs. These QDs were prepared at $230{ }^{\circ} \mathrm{C}$ by adding $\mathrm{P}\left(\mathrm{SiMe}_{3}\right)_{3}$ into a solution containing indium(III) tris(amidinate) as indium precursor, and a mixture of HDA and palmitic acid in a $1: 3$ ratio. Similarly to the previous reports on the synthesis of InP QDs, ${ }^{8,17 a}$ the ${ }^{31} \mathrm{P}$ MAS NMR spectra display several environments for the phosphorus atoms as evidenced by the resonances at $\delta 28,2$ and $-185 \mathrm{ppm}$ in a 8:7:85 ratio (Fig. S9a, ESI $\dagger$ ). The major one is broad and intense and lies in the high-field range typically found for nanoparticulate metal phosphides. The two other resonances arise from surface oxidation, as evidenced by the significant increase in intensity in the ${ }^{31} \mathrm{P}$ CP MAS NMR spectrum (Fig. S9b, $\mathrm{ESI} \dagger$ ). This phenomenon results from the reaction between the acid and the amine that yields to the amide formation and the concomitant in situ water formation. ${ }^{24}$ This side-reaction is clearly supported by the ${ }^{13} \mathrm{C}$ CP MAS NMR spectrum (Fig. 5) which indicates the presence of amide. More importantly, this spectrum provides the first direct observation of the ethyl moiety of an ethoxide fragment $(\delta 60.0,19.1 \mathrm{ppm}$ for the methylene and the methyl groups respectively) at the QDs' surface. ${ }^{10 c, 11 b, 13}$

It is important to stress that this so far unidentified ligand is suspected to play a key role for the isolation and purification processes of QDs. ${ }^{10 c, 11 b, 13}$ The high intensity in this CP MAS NMR spectrum clearly shows that this fragment is in restricted motion, presumably interacting through van der Waals interaction with others surface ligands. Given the absence of peaks in the $\mathrm{OH}$ region of the IR spectrum (Fig. S10, ESI $\dagger$ ), it is probable that the ethoxide moiety belongs to ethoxide ligand rather than hydrogenbonded or trapped ethyl alcohol. ${ }^{10 c}$ This ethoxyde ligand probably forms from the ligand exchange reaction with carboxylate as previously proposed by Hens et al. ${ }^{11 b}$ Last, palmitate completes the picture of the carbon-containing ligands shell as evidenced by its distinctive signal at $\delta 180.5$ corresponding to the carboxylate resonance (Fig. 5). The direct ${ }^{13} \mathrm{C}$ MAS NMR is well-suited for identifying mobile species and the corresponding spectrum shows

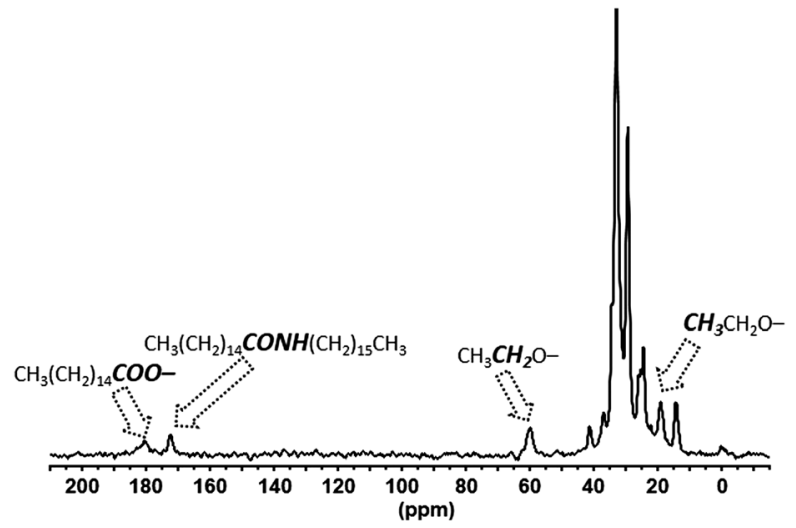

Fig. $5{ }^{13} \mathrm{C}$ CP MAS NMR spectrum (spinning speed $16 \mathrm{kHz}$ ) of InP QDs.

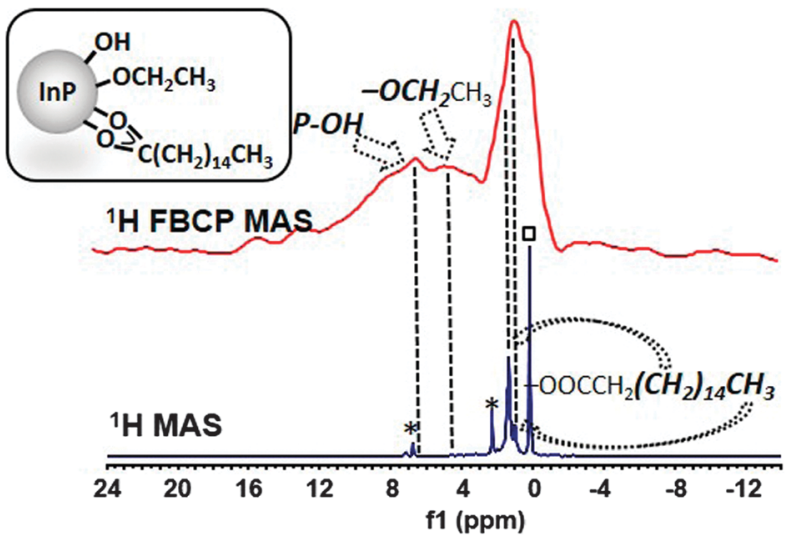

Fig. 6 Comparison of the ${ }^{1} \mathrm{H}$ MAS NMR and FBCP ${ }^{1} \mathrm{H}$ MAS NMR spectra (spinning speed $16 \mathrm{kHz}$ ) of InP QDs (*: residual mesitylene, $\square$ : grease).

residual mesitylene solvent molecules which remain in the sample ( $\delta 136.2$ and $126.1 \mathrm{ppm}$ ) (Fig. S11, ESI $\dagger$ ). This is also evident from the ${ }^{1} \mathrm{H}$ MAS NMR spectrum ( $\delta 6.6$ and $2.1 \mathrm{ppm}$ ) which displays in addition to the characteristic resonances of the long chain palmitate ligands clearly visible at $\delta 1.21$ and 0.83 ppm (Fig. 6). However, when applying the FBCP sequence, the resulting ${ }^{1} \mathrm{H}$ NMR spectrum shows the resonances of the fragments that are located close to the surface. Beyond the resonances of the methylenes and the methyl of palmitate, one can observe new broad peaks at 4.8 and 7.0 ppm (Fig. 6). The first one is consistent with the $\mathrm{CH}_{2}$ of ethoxide identified using ${ }^{13} \mathrm{C}$ CP MAS NMR. The latter resonance belongs to more acidic protons and can be assigned, as for $\operatorname{Cd}_{3} \mathrm{P}_{2}$ QDs, to the hydroxyl fragments involved in different hydrogenbonded environments with water molecules. ${ }^{21}$

In conclusion, we have described the potentialities of the conventional solid-state MAS NMR for providing a comprehensive overview of phosphides QDs. Remarkably, this allows the identification of new species that were so far invisible using IR and NMR spectroscopies because of the broadening of the surface resonances and of the strong signal of fragments located further from the surface. Moreover, the upgraded NMR-based approach called ${ }^{1} \mathrm{H}$ Forth and Back Cross Polarization (FBCP) MAS enables the unprecedented visualization of ${ }^{1} \mathrm{H}$ signals of rigid fragments or ligands at the surface of phosphides NCs. This is achieved thanks to selective enhancement of ${ }^{1} \mathrm{H}$ nuclei at the inorganic surface. This experiment has been shown to be highly sensitive since very minor species can be identified (as low as a few percent) and thus, paves the way for re-examining in detail the surface of NPs and identifying the actual surface state. We have demonstrated the applicability of this approach to phosphide NCs and we believe that this approach can be extended to other NPs incorporating NMR active nuclei such as metals, metal chalcogenides, pnictogenides or halides.

\section{Acknowledgements}

This work was supported by the Université Paul Sabatier, the Région Midi-Pyrénées, the CNRS, the Institut National des Sciences Appliquées of Toulouse, the European Commission for ERC Grant No. 306719 and the Agence Nationale pour la Recherche 
(Project ANR-13-IS10-0004-01). W.-S. O. is grateful to the European Commission for a postdoctoral grant (ERC Grant No. 306719). E. A. B. is grateful to Marie Curie Actions and Campus France for a PRESTIGE post-doc fellowship (FP7/2007-2013) under REA grant agreement no. PCOFUND-GA-2013-609102.

\section{Notes and references}

1 (a) R. Costi, A. E. Saunders and U. Banin, Angew. Chem., Int. Ed., 2010, 49, 4878; (b) D. V. Talapin, J.-S. Lee, M. V. Kovalenko and E. V. Shevchenko, Chem. Rev., 2010, 110, 389.

2 M. V. Kovalenko, L. Manna, A. Cabot, Z. Hens, D. V. Talapin, C. R. Kagan, V. I. Klimov, A. L. Rogach, P. Reiss, D. J. Milliron, P. Guyot-Sionnest, G. Konstantatos, W. J. Parak, T. Hyeon, B. A. Korgel, C. B. Murray and W. Heiss, ACS Nano, 2015, 9, 1012.

3 (a) S. Tamang, C. Lincheneau, Y. Hermans, S. Jeong and P. Reiss, Chem. Mater., 2016, 28, 2491; (b) S. Carenco, D. Portehault, C. Boissiere, N. Mezailles and C. Sanchez, Chem. Rev., 2013, 113, 7981.

4 (a) B. A. Glassy and B. M. Cossairt, Chem. Commun., 2015, 51, 5283; (b) M. H. Mobarok, E. J. Luber, G. M. Bernard, L. Peng, R. E. Wasylishen and J. M. Buriak, Chem. Mater., 2014, 26, 1925; (c) S. Miao, T. Yang, S. G. Hickey, V. Lesnyak, B. Rellinghaus, J. Xu and A. Eychmüller, Small, 2013, 9, 3415 .

5 (a) D. Franke, D. K. Harris, L. Xie, K. F. Jensen and M. G. Bawendi, Angew. Chem., Int. Ed., 2015, 54, 14507; (b) D. C. Gary, B. A. Glassy and B. M. Cossairt, Chem. Mater., 2014, 26, 1734; (c) P. M. Allen, B. J. Walker and M. G. Bawendi, Angew. Chem., Int. Ed., 2010, 49, 760; (d) D. C. Gary, M. W. Terban, S. J. L. Billinge and B. M. Cossairt, Chem. Mater., 2015, 27, 1432; (e) L. Xie, D. K. Harris, M. G. Bawendi and K. F. Jensen, Chem. Mater., 2015, 27, 5058; $(f)$ D. C. Gary and B. M. Cossairt, Chem. Mater., 2013, 25, 2463.

6 (a) D. C. Gary, S. E. Flowers, W. Kaminsky, A. Petrone, X. Li and B. M. Cossairt, J. Am. Chem. Soc., 2016, 138, 1510; (b) K. Kim, D. Yoo, H. Choi, S. Tamang, J.-H. Ko, S. Kim, Y.-H. Kim and S. Jeong, Angew. Chem., Int. Ed., 2016, 55, 3714.

7 (a) M. A. Boles, D. Ling, T. Hyeon and D. V. Talapin, Nat. Mater., 2016, 15, 141; (b) J. S. Owen, Science, 2015, 347, 615; (c) D. A. Hines and P. V. Kamat, ACS Appl. Mater. Interfaces, 2014, 6, 3041; (d) A. J. Morris-Cohen, M. Malicki, M. D. Peterson, J. W. J. Slavin and E. A. Weiss, Chem. Mater., 2013, 25, 1155; (e) Y. Yin and A. P. Alivisatos, Nature, 2005, 437, 664 .

8 (a) A. Cros-Gagneux, F. Delpech, C. Nayral, A. Cornejo, Y. Coppel and B. Chaudret, J. Am. Chem. Soc., 2010, 132, 18147; (b) H. Virieux, M. Le Troedec, A. Cros-Gagneux, W.-S. Ojo, F. Delpech, C. Nayral, H. Martinez and B. Chaudret, J. Am. Chem. Soc., 2012, 134, 19701.

9 (a) L. Marbella and J. Millstone, Chem. Mater., 2015, 27, 2721; (b) C. Bonhomme, C. Gervais and D. Laurencin, Prog. Nucl. Magn. Reson. Spectrosc., 2014, 77, 1.

10 (a) Z. Hens and J. C. Martins, Chem. Mater., 2013, 25, 1211; (b) J. De Roo, F. Van den Broeck, K. De Keukeleere,
J. C. Martins, I. Van Driessche and Z. Hens, J. Am. Chem. Soc., 2014, 136, 9650; (c) N. C. Anderson, M. P. Hendricks, J. J. Choi and J. S. Owen, J. Am. Chem. Soc., 2013, 135, 18536; (d) J. De Roo, Y. Justo, K. De Keukeleere, F. Van den Broeck, J. C. Martins, I. Van Driessche and Z. Hens, Angew. Chem., Int. Ed., 2015, 54, 6488.

11 (a) M. H. Mobarok and J. M. Buriak, Chem. Mater., 2014, 26, 4653; (b) A. Hassinen, I. Moreels, K. De Nolf, P. F. Smet, J. C. Martins and Z. Hens, J. Am. Chem. Soc., 2012, 134, 20705.

12 (a) D. Zherebetskyy, M. Scheele, Y. Zhang, N. Bronstein, C. Thompson, D. Britt, M. Salmeron, P. Alivisatos and L.-W. Wang, Science, 2014, 344(6190), 1380; (b) V. Malgras, A. Nattestad, Y. Yamauchi, S. X. Doua and J. H. Kim, Nanoscale, 2015, 7, 5706.

13 B. Shakeri and R. W. Meulenberg, Langmuir, 2015, 31, 13433. 14 J. P. Yesinowski, A. P. Purdy, H. Wu, M. G. Spencer, J. Hunting and F. J. Di Salvo, J. Am. Chem. Soc., 2006, 128, 4952.

15 (a) M. Tomaselli, J. L. Yarger, M. Bruchez, R. H. Havlin, D. de Graw, A. Pines and A. P. Alivisatos, J. Chem. Phys., 1999, 110, 8861; (b) N. El Hawi, C. Nayral, F. Delpech, Y. Coppel, A. Cornejo, A. Castel and B. Chaudret, Langmuir, 2009, 7540; (c) D. D. Lovingood, R. Achey, A. K. Paravastu and G. F. Strouse, J. Am. Chem. Soc., 2010, 132, 3344; (d) F. Iacono, C. Palencia, L. de la Cueva, M. Meyns, L. Terracciano, A. Vollmer, M. J. de la Mata, C. Klinke, J. M. Gallego, B. H. Juarez and R. Otero, ACS Nano, 2013, 7, 2559.

16 J. Schaefer, R. A. Mc Kay and E. O. Stejskal, J. Magn. Reson., 1979, 34, 443.

17 T. Tran, H. Bildsøe, H. Jakobsen and J. Skibsted, J. Magn. Reson., 2012, 221, 19.

18 (a) N. Baccile, G. Laurent, C. Bonhomme, P. Innocenzi and F. Babonneau, Chem. Mater., 2007, 19, 1343; (b) N. Folliet, C. Roil, S. Bégu, A. Aubert, T. Mineva, A. Goursot, K. Selvaraj, L. Duma, F. Tielens, F. Mauri, G. Laurent, C. Bonhomme, C. Gervais, F. Babonneau and T. Azaïs, J. Am. Chem. Soc., 2011, 133, 16815.

19 (a) S. M. Holl, T. Kowalewski and J. Schaefer, Solid State Nucl. Magn. Reson., 1996, 6, 39; (b) N. L. Adolphi, R. D. Stoddard, S. C. Goel, W. E. Buhro, P. C. Gibbons and M. S. Conradi, J. Phys. Chem. Solids, 1992, 53, 1275.

20 W.-S. Ojo, S. Xu, F. Delpech, C. Nayral and B. Chaudret, Angew. Chem., Int. Ed., 2012, 51, 738.

21 (a) J. P. Yesinowski and H. Eckert, J. Am. Chem. Soc., 1987, 109, 6274; (b) J. Arends, J. Christoffersen, M. R. Christoffersen, H. Eckert, B. O. Fowler, J. C. Heughebaert, G. H. Nancollas, J. P. Yesinowski and S. J. Zawackiw, J. Cryst. Growth, 1987, 84, 515.

22 J. M. Luther, M. Law, Q. Song, C. L. Perkins, M. C. Beard and A. J. Nozik, ACS Nano, 2008, 2, 271.

23 (a) J. M. Luther and J. M. Pietryga, ACS Nano, 2013, 7, 1845; (b) C. N. Valdez, A. M. Schimpf, D. R. Gamelin and J. M. Mayer, ACS Nano, 2014, 8, 9463.

24 (a) H. Wu, Y. Yang and Y. C. Cao, J. Am. Chem. Soc., 2006, 128, 16522; (b) M. Protière and P. Reiss, Chem. Commun., 2007, 2417. 